\title{
$\mathrm{EPON}$ 에서의 효율성 향상을 위한 가변 최대 전송 윈도우를 이용한 IPS 기반의 동적 대역폭 할당 알고리즘
}

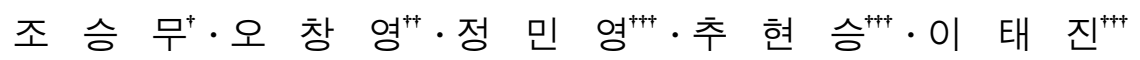

요 약

\begin{abstract}
본 논문은 EPON(Ether Passive Optical Network)에서 채널 사용률을 개선하기 위한 방안으로 가변 최대 전송 윈도우를 이용한 동적 대역 폭 할당(DBA-AMTW: Dynamic Bandwidth Allocation with Adaptive Maximum Transmission Window) 알고리즘을 제안한다. EPON에서의 폴링 기법은 채널 사용률을 결정하고 DBA 및 스케줄링 기법의 사용에 영향을 미친다. IPS(Interleaved Polling with Stop)에 기반을 둔 DBA 방식은 합리적인 전송 윈도우 할당이 가능한 장점을 갖지만, 채널 비사용 구간이 발생하여 채널 사용률이 저하되는 단점을 가진다. 제안하는 가변 최대 전송 윈도우를 이용한 동적 대역폭 할당 알고리즘은 채널 비사용 구간을 효율적으로 감소시키는 동시에 모든 ONU의 REPORT 메 시지를 고려한 합리적인 채널할당이 가능한 특징을 가진다. 각 $\mathrm{ONU}$ 는 개별적인 최대 전송 윈도우의 크기를 가지고 이러한 최대 전송 윈도우 의 크기는 이전 사이클에서 결정된다. 시뮬레이션을 통해 제안하는 동적 대역폭 할당 방식이 기존 방식에 비해 처리율과 평균 지연 시간에 대 한 성능을 향상시킴을 확인하였다.
\end{abstract}

키워드 : EPON, 동적 대역폭 할당, IPS

\section{IPS-based Dynamic Bandwidth Allocation Algorithm with Adaptive Maximum Transmission Window to Increase Channel Utilization in EPON}

\author{
Seung-Moo $\mathrm{Cho}^{+} \cdot$ Chang-Yeong $\mathrm{Oh}^{++} \cdot$ Min Young Chung ${ }^{+++} \cdot$ Hyunseung Choo ${ }^{+++} \cdot$ Tae-Jin Lee ${ }^{+++}$
}

\begin{abstract}
This paper proposes a dynamic bandwidth allocation (DBA) algorithm with adaptive maximum transmission window (DBA-AMTW) to increase channel utilization in Ethernet passive optical networks (EPONs). A polling mechanism in EPON determines channel utilization and puts constraints on DBA algorithm and scheduling. DBA algorithms based on interleaved polling with stop (IPS) allocate transmission windows to optical network units (ONU) considering requests of all ONUs. However channel idle time when any ONU does not transmit packets decreases channel utilization. Proposed DBA-AMTW improves efficiency of a network and allocates transmission windows effectively by appropriate DBA computation from REPORT messages of all ONUs. An adaptive maximum transmission window for each ONU determined by a DBA computation in the previous scheduling cycle. Simulation results show that the proposed DBA algorithm improves performance of throughput and average delay time.
\end{abstract}

Keywords : EPON, Dynamic Bandwidth Allocation, Interleaved Polling with Stop

\section{1. 서 론}

인터넷 가입자의 증가 및 멀티미디어 서비스의 대중화로 인한 접속 망의 병목 현상을 해결하기 위한 방안으로 광 접 속 망이 주목 받고 있다[1,2]. 또한, 유무선 통합망에 대한

※ 이 논문은 2008 년 정부(교육과학기술부)의 재원으로 한국학술진흥 재단의 지원 사업(KRF-2008-314-D00296)과 지식경제부 및 정보통신연구진흥워

의 대학 IT연구센터 지원사업(IITA-2009-C1090-0902-0005, -0046)의 연 구결과로 수행되었음

† 정 회 원: 삼성전자 $\mathrm{DMC}$ 부문 무선사업부 연구원

†† 정 회 원: 성균관대학교 정보통신공학부 공학석사과정

††† 종신회원 : 성균관대학교 정보통신공학부 부교수

논문접수: 2009년 3월 25일

수 정 일 : 1 차 2009년 5월 8일

심사완료 : 2009년 6월 11일
관심이 증가되고 있고, 다양한 유무선 통합 서비스를 지원 하기 위해 FTTH(Fiber to the Home)의 구현이 필수적으로 요구된다[3]. $\mathrm{EPON}$ 시스템은 이더넷 장비를 그대로 사용 가능하고 수동 광 소자를 사용하므로 유지 및 보수가 용이 하기 때문에 FTTH 구축에 가장 적합한 해결책으로 주목받 고 있다[4,5]. EPON은 하나의 OLT(Optical Line Terminator) 와 다수의 $\mathrm{ONU}($ Optical Network Unit)가 $1: \mathrm{N}$ 광분배기를 통해 연결된 구조를 가진다. 버스, 링, 트리 형태를 기반으로 구축이 가능하지만 일반적으로 트리 형태에 기반을 둔 구조 를 사용한다. (그림 1)은 이러한 트리 형태에 기반을 둔 $\mathrm{EPON}$ 의 구조를 나타낸다. 트리 형태에 기반을 둔 구조는 점대점(Point-to-Point) 연결에 비해 OLT에 설치되는 송수신 


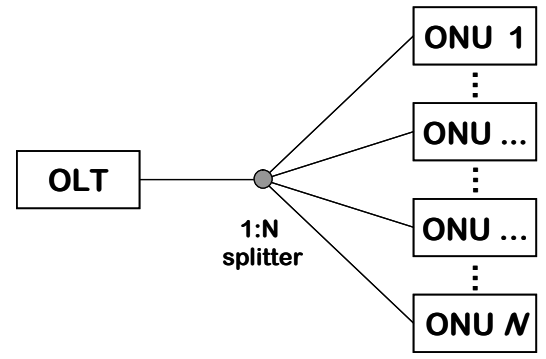

(그림 1) EPON 구성 예

기의 수를 줄일 수 있는 장점이 있고, 외부의 전원 연결이 필 요 없는 수동 분배기를 사용하여 유지 및 보수가 용이하다.

$\mathrm{EPON}$ 에서는 상향 및 하향 전송을 위해 각각 하나의 파 장 채널을 사용한다. OLT에서 송신한 신호는 광분배기를 거치면서 모든 $\mathrm{ONU}$ 에게 전달이 된다. 따라서 $\mathrm{ONU}$ 가 수신 하게 되는 신호의 세기는 OLT에서 전송한 신호의 세기에 비해 그 크기가 $1 / \mathrm{N}$ 로 줄어들게 되지만 모든 ONU가 OLT 에서 송신한 신호를 수신하는 것이 가능하므로 이더넷과 동 일하게 단순한 방송(broadcasting) 프로토콜을 적용하여 하 향전송이 가능하다. 그러나 $\mathrm{ONU}$ 에서 $\mathrm{OLT}$ 로 패킷을 전송하 는 상향전송의 경우 이더넷의 다중접속 프로토콜인 CSMA (Carrier Sensed Multiple Access) 프로토콜을 그대로 사용 할 수 없다. 이는 광분배기의 방향성에 의한 것으로 $\mathrm{ONU}$ 에 서 전송한 패킷은 광분배기를 거치면서 다른 $\mathrm{ONU}$ 에게는 전 송되지 않고 OLT에서만 수신된다. IEEE 802.3ah working group는 효율적인 상향전송 링크의 공유를 위해 $\mathrm{MPCP}$ (Multi-Point Control Protocol)의 사용을 제안하였다[6]. $\mathrm{MPCP}$ 에는 네트워크 구성을 위한 발견 및 등록에 관한 절 차뿐만 아니라 $\mathrm{ONU}$ 간의 효율적인 상향 링크 공유를 위해 $\mathrm{REPORT}$ 와 GATE 메시지의 사용을 정의하였다. 그러나 대 역폭 할당 알고리즘은 $\mathrm{MPCP}$ 에 제공되어 있지 않기 때문에 서비스의 요구 조건 및 공평성 등을 고려한 효율적인 대역 폭 할당에 대한 연구가 필요하다[7].

$\mathrm{EPON}$ 에서는 폴링 기반 $\mathrm{DBA}$ 에 대한 연구가 진행 되었 으며, IP(Interleaved Polling) 방식과 IPS(Interleaved Polling with Stop) 방식으로 구분된다[6]. IP 방식은 한 ONU로부터 REPORT 메시지를 수신하면 OLT가 즉각적으로 GATE 메 시지를 전송하는 방식으로 채널을 효율적으로 사용할 수 있 는 장점을 가진다. IPACT(Interleaved Polling with Adaptive Cycle Time) 기법은 이러한 IP에 기반을 둔 DBA 방식으로 대역폭 할당을 위해 고정 대역폭 할당, 제안 대역 폭 할당, 고정 예측할당 및 선형 예측할당 등의 방식이 제 안되었다[8]. [9]에서는 IPACT의 지연시간에 대한 성능을 향상시키기 위해 현재 사이클에 도달한 패킷의 양을 추정하 여 이를 $\mathrm{DBA}$ 에 반영하는 방식을 제안하였다. 이러한 IP에 기반을 둔 $\mathrm{DBA}$ 방식은 채널 사용 효율성과 지연시간에 대 한 개선 효과를 얻을 수 있지만, 모든 ONU의 REPORT 메 시지를 고려한 합리적인 $\mathrm{DBA}$ 가 불가능한 단점을 가진다. 기존 $\mathrm{IP}$ 기반 $\mathrm{DBA}$ 방식들의 단점을 보완하고자 [16]에서는 최대 전송윈도우 크기의 동적변화기법을 적용한 $\mathrm{IP}$ 기반의
$\mathrm{DBA}$ 방식을 제안하였으나 모든 $\mathrm{ONU}$ 의 $\mathrm{QoS}$ 보장을 위해 서는 한계가 있다. [10]에서는 EPON에서 QoS(Quality of Service)를 보장하기 위해 IPS에 기반을 둔 $\mathrm{DBA}$ 방식을 제 안하였다. IPS에 기반을 둔 $\mathrm{DBA}$ 방식을 사용할 경우 $\mathrm{DBA}$ 계산이 진행되는 동안 파장 채널을 사용할 수 없는 시간 구 간이 발생하게 된다. [10]에서는 이러한 채널 비사용 구간을 줄이기 위한 방안으로 최소보장 대역폭보다 적은 대역폭을 요구한 $\mathrm{ONU}$ 에게 우선적으로 전송기회를 주는 방안을 제시 하였다. 그러나 채널 비사용 구간에 대한 근본적인 해결책 을 제시하고 있지 못하기 때문에 [11]에서는 이를 해결하기 위한 방안으로 우선적으로 IPACT의 제한 대역폭 할당을 이용해 모든 $\mathrm{ONU}$ 에게 즉각적으로 전송윈도우를 할당하고, $\mathrm{DBA}$ 계산이 끝난 후 다시 $\mathrm{ONU}$ 들에게 재전송 기회를 주는 방안을 제안하였다. [11]에서 제안된 방식은 다중파장 채널 환경을 위해 제안된 방식이지만 단일 파장 채널을 사용하는 $\mathrm{EPON}$ 환경에도 그대로 적용이 가능하다.

본 논문에서는 IPS에 기반을 둔 $\mathrm{DBA}$ 알고리즘의 단점인 채널 비사용구간의 발생을 방지하기 위한 방안으로 가변 최 대 전송 윈도우(AMTW: Adaptive Maximum Transmission Window)를 이용한 $\mathrm{DBA}$ 알고리즘을 제안한다. 제안하는 $\mathrm{DBA}$ 알고리즘은 채널 비사용 구간을 효과적으로 감소시키 는 동시에 모든 $\mathrm{ONU}$ 의 REPORT 메시지를 고려한 효과적 인 $\mathrm{DBA}$ 가 가능하다. 2장에서는 $\mathrm{EPON}$ 에서의 폴링 및 스케 줄링에 대해 설명하고, 관련 연구에 대해 소개한다. 3장에서 는 제안하는 가변 최대 전송 윈도우를 이용한 $\mathrm{DBA}$ 알고리 즘에 대해 설명하고, 4장에서 시뮬레이션을 위한 $\mathrm{EPON}$ 환 경을 서술하고 제안 $\mathrm{DBA}$ 와 관련연구에서 소개된 $\mathrm{DBA}$ 의 성능을 비교한다. 마지막으로 5장에서 결론을 맺는다.

\section{2. $\mathrm{EPON}$ 의 $\mathrm{DBA}$ 및 관련 연구}

\section{1 폴링 (Polling)}

$\mathrm{EPON}$ 에서는 다수의 $\mathrm{ONU}$ 들이 상향 채널을 공유하기 때 문에 효율적인 채널 사용을 위해 폴링 기법이 필요하다. $\mathrm{MPCP}$ 에는 이러한 폴링 절차를 위해 REPORT 메시지와 GATE 메시지 사용이 정의되어 있다. 각 $\mathrm{ONU}$ 는 REPORT 메시지를 사용하여 전송에 필요한 전송윈도우의 크기를 OLT에게 요청하게 되고, OLT는 이러한 REPORT 메시지 를 사용하여 각 $\mathrm{ONU}$ 가 전송을 시작하는 시점과 전송을 마 무리하는 시점을 결정한다. OLT에서 결정된 각 $\mathrm{ONU}$ 의 전 송윈도우에 대한 정보는 GATE 메시지를 통해 다시 $\mathrm{ONU}$ 에게 전송되고, 이러한 절차를 통해 $\mathrm{ONU}$ 는 상향 전송을 위 한 전송 윈도우를 할당 받는다. 따라서 폴링 기법은 대역폭 할당 알고리즘 및 스케줄링 기법의 사용에 영향을 미치고, 네트워크의 효율적 사용을 좌우한다.

[6]에 나타난 IP 기법은 OLT가 ONU로부터 REPORT 메 시지를 받으면 즉시 GATE 메시지를 전송하는 방식으로 가 장 단순한 절차를 가진다. (그림 $2(\mathrm{a})$ )는 이러한 IP 기법을 사용할 경우 REPORT 메시지와 GATE 메시지 간 전송절차 


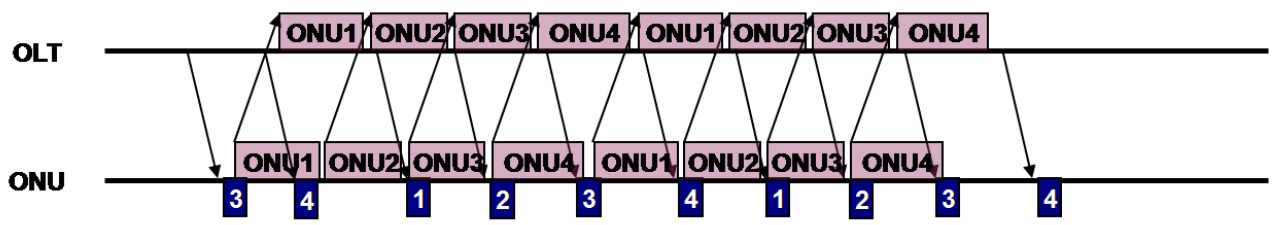

(a) IP(Interleaved Polling)

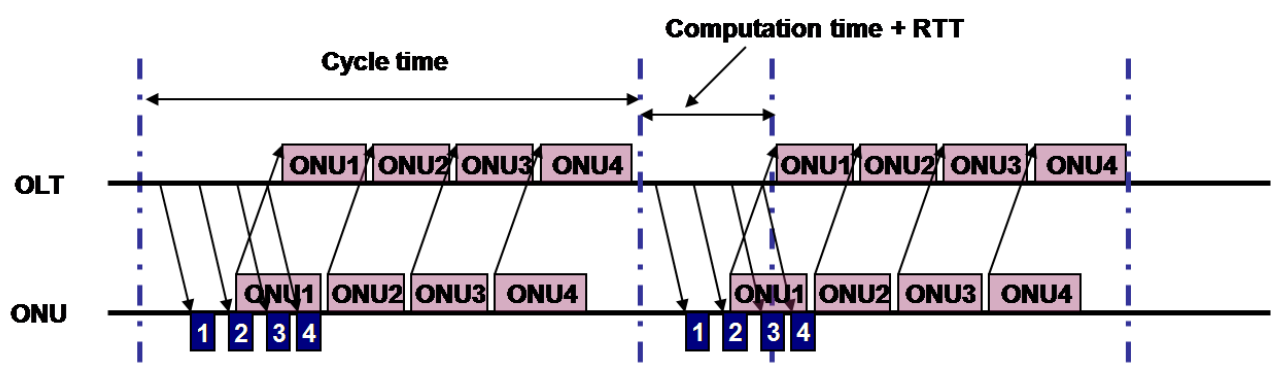

(b) IPS(Interleaved Polling with Stop)

(그림 2) EPON에서 폴링 방식에 따른 메시지 교환 절차 (a) IP, (b) IPS

를 나타낸다. OLT는 ONU로부터 REPORT 메시지를 수신 하면 즉시 대역폭 할당 알고리즘에 의해 전송윈도우의 크기 및 전송 시작 시점을 결정하고 바로 $\mathrm{ONU}$ 에게 GATE 메시 지를 전송하기 때문에 채널 사용율을 극대화 시킬 수 있는 장점을 가진다. 그러나 OLT는 모든 $\mathrm{ONU}$ 의 전송 요구량을 고려하여 대역폭을 결정할 수 없기 때문에 서비스의 요구조 건 및 $\mathrm{ONU}$ 간 공평성을 고려한 대역폭 할당이 어렵다.

(그림 2(b))는 IPS를 사용할 경우 REPORT 메시지와 GATE 메시지가 OLT와 ONU 사이에서 어떠한 방식으로 전송되는지를 나타내고 있다. IPS는 현재 스케줄링 사이클 내에서 모든 ONU로부터 REPORT 메시지를 전송받은 후에 다음 스케줄링 사이클을 시작한다. 따라서 모든 $\mathrm{ONU}$ 의 대 역폭 요구량을 고려한 합리적인 $\mathrm{DBA}$ 가 가능하다. 이러한 방식을 사용하여 $\mathrm{ONU}$ 간의 공평성과 서비스의 요구조건을 만족시킬 수 있지만 모든 ONU로부터 REPORT 메시지를 수신한 후에 $\mathrm{DBA}$ 과정을 거치고 GATE 메시지를 전송함 으로써 채널을 사용하지 못하는 구간이 발생하는 단점을 가 진다. 이러한 채널 비사용 구간은 한정된 파장 채널을 사용 하는 $\mathrm{EPON}$ 에서 시스템의 효율을 저하시키는 역할을 한다.

\section{2 스케줄링}

$\mathrm{EPON}$ 에서 사용되는 스케줄링 기법은 크게 inter-ONU 스 케줄링과 intra-ONU 스케줄링으로 구분된다. Intra-ONU 스 케줄링은 멀티 서비스를 지원하기 위해 제안이 되었고, 각 $\mathrm{ONU}$ 의 내부 큐에서 어떤 서비스의 패킷을 먼저 전송할지에 대한 우선순위를 결정한다. 각 $\mathrm{ONU}$ 의 트래픽은 우선순위에 의해 $\mathrm{EF}$ (Expedited Forwarding), $\mathrm{AF}$ (Assured Forwarding), $\mathrm{BE}$ (Best Effort)로 구분되고, $\mathrm{EF}$ 트래픽은 지연에 민감하고 전송률 보장이 요구되는 트래픽이고, $\mathrm{AF}$ 는 지연에 민감하지
는 않으나 전송률 보장을 요구하는 트래픽이다[12][13]. 또한 $\mathrm{BE}$ 는 지연 시간과 전송률의 보장을 요구하지 않는 트래픽 을 의미한다. $\mathrm{MPCP}$ 는 기본적으로 하나의 REPORT 메시지 에 8개의 큐 상태에 대한 정보를 담을 수 있고, 이러한 $\mathrm{ONU}$ 의 각 트래픽에 대한 정보는 $\mathrm{OLT}$ 로 전송된다. $\mathrm{EPON}$ 에서 intra-ONU 스케줄링 방법으로 $\mathrm{PQ}$ (Priority Queueing), $\mathrm{SPQ}$ (Strict Priority Queueing) 등의 방법이 있고, 각 방식은 $\mathrm{ONU}$ 내부에서 언제 다음 전송할 패킷을 결정할지에 따라 구분된다. $\mathrm{PQ}$ 방식은 $\mathrm{ONU}$ 의 전송 윈도우가 시작되는 시점 에서 자신에게 할당된 전송 윈도우에 맞게 패킷의 전송 순 위를 고려하는 방식이고, $\mathrm{SPQ}$ 방식은 패킷이 전송될 때마 다 다음 전송할 패킷을 결정하는 방식이다. 따라서 $\mathrm{SPQ}$ 방 식을 사용할 경우 자신의 전송 윈도우 시작 시간 이후에 큐 에 입력된 높은 우선순위의 패킷을 낮은 우선순위의 패킷보 다 먼저 처리할 수 있다.

Inter-ONU 스케줄링은 각 스케줄링 사이클에서 어떠한 $\mathrm{ONU}$ 가 먼저 전송할 지를 결정하며, $\mathrm{ONU}$ 내부의 스케줄러 에 의한 intra-ONU 스케줄링과 다르게 OLT에서 각 $\mathrm{ONU}$ 의 전송 순서를 결정한다. OLT 내부의 스케줄러에서 결정 된 전송 우선순위에 따라 각 $\mathrm{ONU}$ 의 전송 시점에 대한 정 보를 GATE 메시지를 통해 ONU에게 전송하게 된다. [14] 에서는 inter-ONU 스케줄링을 크게 online 스케줄링, offline 스케줄링, just-in-time online 스케줄링의 방법으로 구분하 였다. 이러한 스케줄링의 구분은 폴링 기법과 밀접한 연관 을 가지고 있으며 [15]에서는 online 스케줄링에 기반을 둔 여러 스케줄링을 적용할 경우 inter-ONU 스케줄링이 시스 템의 성능에 어떠한 영향을 주는지를 나타내고 있다. 
2.3 IPS 기반의 DBA 관련 연구

\subsubsection{Assi 등이 제안한 $\mathrm{DBA}$ 방법들}

Assi 등은 [10]에서 $\mathrm{EPON}$ 에서 $\mathrm{QoS}$ 를 지원하기 위한 두 가지 DBA 방안을 제안하였다(DBA_Assi1, DBA_Assi2). DBA_Assi1은 (그림 2(b))에 나타난 폴링 방식을 사용하여 모든 ONU의 REPORT 메시지를 수신한 후에 OLT에서 $\mathrm{ONU}$ 에게 할당할 대역폭을 계산하게 하고, 계산이 종료된 후 GATE 메시지를 모든 ONU에게 전송하는 방식을 사용 한다. 각 $\mathrm{ONU}$ 의 전송 기회 및 전송률을 보장하기 위해 최 소 보장 대역폭 $B_{M I N}$ 을 정의하고 모든 $\mathrm{ONU}$ 는 매 스케줄링 사이클 마다 $B_{M I N}$ 에 해당하는 대역폭을 할당 받을 수 있다. 모든 $\mathrm{ONU}$ 가 $B_{M I N}$ 에 해당하는 대역폭을 할당 받게 될 경우 전송할 데이터가 적은 $\mathrm{ONU}$ 의 전송 윈도우 중 일부가 사용 되지 않는 현상이 발생하게 된다. 이러한 현상은 네트워크 전체의 성능을 저하시키기 때문에 DBA_Assi1에서는 최소 보장 대역폭 보다 적은 대역폭을 요구한 $\mathrm{ONU}$ 에게는 요구 한 대역폭만을 할당하고, 최소 보장 대역폭 이상의 대역폭 을 요구한 $\mathrm{ONU}$ 에게는 최대 스케줄링 사이클의 크기 및 다 른 $\mathrm{ONU}$ 의 요구량을 고려하여 대역폭을 할당하는 방식을 사 용하였다. 최소 보장 대역폭 $B_{M I N}$ 은 다음과 같이 정의된다.

$$
B_{\text {MIN }}=\left(T_{\text {cycle }}-T_{\text {guard }} \times N\right) \times\left(R_{\lambda} / 8\right) / N
$$

여기서 $T_{c y c l}$ 은 최대 스케줄링 사이클의 크기를 나타내 고, $T_{\text {guard }}$ 는 전송 윈도우 사이의 보호 구간을 의미한다. $N$ 은 하나의 OLT에 연결된 $\mathrm{ONU}$ 의 개수를 의미하고, $R_{\lambda}$ 는 파장 채널의 전송률을 나타낸다. ONU $i$ 가 할당받는 대역폭
$B_{g r a n t}^{i}$ 는 다음과 같이 정의 된다.

$$
B_{\text {grant }}^{i}= \begin{cases}B_{\text {request }}^{i} & , \text { for } B_{\text {request }}^{i} \leq B_{\text {MIN }} \\ B_{\text {MIN }}+B_{\text {excess }}^{i}, & \text { for } B_{\text {request }}^{i}>B_{M I N}\end{cases}
$$

여기서 $B_{\text {request }}^{i}$ 는 $\mathrm{ONU} i$ 의 요구량을 의미하고, 최소 보 장 대역폭보다 적은 대역폭을 요구한 $\mathrm{ONU}$ 의 집합을 $L$, 최 소 보장 대역폭보다 많은 대역폭을 요구한 ONU의 집합을 $H$ 라고 할 때 $B_{e x c e s s}^{i}$ 는 다음과 같이 정의된다.

$$
B_{\text {excess }}^{h}=\frac{B_{\text {request }}^{h} \times \sum_{l \in L}\left(B_{\text {MIN }}-B_{\text {request }}^{l}\right)}{\sum_{h \in H} B_{\text {request }}^{h}}
$$

DBA_Assi1을 대역폭 할당 알고리즘으로 적용할 경우 모 든 $\mathrm{ONU}$ 에게 최소 전송률을 보장하는 동시에 대역폭을 고 려한 효율적인 대역폭 할당이 가능하다. 그러나 DBA_Assi1 은 IPS에 기반을 두고 있기 때문에 채널 비사용 구간으로 인해 효율성이 저하되는 단점을 가진다. 최소 보장 대역폭 보다 적은 대역폭을 요구한 $\mathrm{ONU}$ 의 경우 요구량만큼 대역 폭을 할당 받기 때문에 OLT는 모든 ONU로부터의 REPORT 메시지를 수신하기 전에 계산과정을 거치지 않고 GATE 메시지를 전송하는 것이 가능하다. DBA_Assi2는 이 러한 특성을 이용하여 최소 보장 대역폭보다 적은 대역폭을 요구한 $\mathrm{ONU}$ 에게 즉각적으로 $\mathrm{GATE}$ 메시지를 전송함으로 써 채널 비사용 구간에서 상향 전송이 가능하도록 하였다. (그림 3(a))는 DBA_Assi2의 REPORT 및 GATE 메시지 전

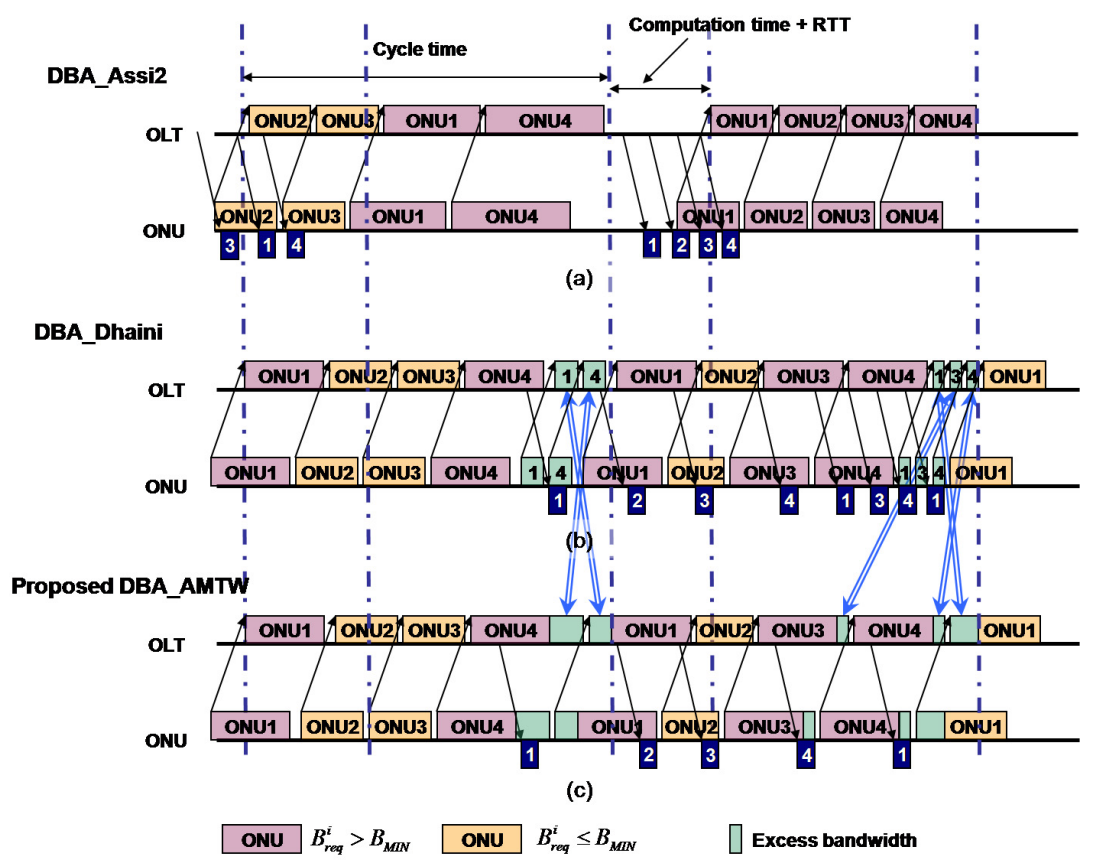

(그림 3) 동적 대역폭 할당 알고리즘에 따른 메시지 교환 절차

(a) DBA_Assi2, (b) DBA_Dhaini, (c) proposed DBA-AMTW 
송 절차를 나타낸다. DBA_Assi2는 DBA_Assi1과 동일한 할당 대역폭 계산 과정을 거치지만 메시지 전송 절차 및 전 송 순서의 변화를 통해 채널 사용 효율을 높이는 장점을 가 진다. 그러나, 그림에서의 두 번째 사이클과 같이 모든 $\mathrm{ONU}$ 가 최소 보장 대역폭 보다 많은 대역폭을 요구할 경우 채널 비사용 구간에서 전송 가능한 $\mathrm{ONU}$ 가 존재하지 않기 때문에 DBA_Assi1과 동일하게 동작하는 한계를 가진다.

\subsubsection{Dhaini 등이 제안한 $\mathrm{DBA}$ 방법들}

Dhaini 등은 다수의 파장 채널을 사용하는 $\mathrm{TDM} / \mathrm{WDM}$ $\mathrm{EPON}$ 환경에서 동적 대역폭 할당을 위한 세 가지 알고리즘 을 제시하였다[11]. 그 중 두 가지 알고리즘은 각각 [10]에서 제안된 DBA_Assi1과 DBA_Assi2를 다중 파장 채널을 사용 하는 환경으로 확장시킨 것으로, 동적 대역폭 할당을 위한 계산과정은 $\mathrm{EPON}$ 에서 제안된 DBA_Assi1, DBA_Assi2와 동일하고 파장을 할당하기 위한 방안으로 $\mathrm{NAJF}(\mathrm{Next}$ Available Job First)의 방식을 사용한다. NAJF는 가장 먼저 사용가능한 파장채널을 가장 높은 전송 우선순위를 가지는 $\mathrm{ONU}$ 에게 할당하는 방식으로 구현이 용이한 장점을 가진다. DBA_Assi1과 DBA_Assi2를 다수 파장 채널을 사용하는 $\mathrm{EPON}$ 환경으로 확장시킨 알고리즘은 단일 파장을 사용하 는 $\mathrm{EPON}$ 의 $\mathrm{DBA}$ 에서 가지고 있던 단점을 그대로 포함하고 있다. DBA_Assi1과 DBA_Assi2의 단점인 채널 비사용 구 간의 발생을 줄이기 위한 방안으로 [11]에서는 새로운 동적 대역폭 할당 알고리즘(DBA_Dhaini)을 제안하였다.

DBA_Dhaini는 채널할당 방식으로 해당 논문에서 소개된 다른 두 가지 대역폭 할당 알고리즘과 동일한 NAJF 방식을 사용하고, 단일 파장 채널을 사용하는 $\mathrm{EPON}$ 환경에 그대로 적용 가능한 특징을 가진다. 또한 모든 $\mathrm{ONU}$ 의 대역폭 요구 량을 반영한 대역폭 할당 계산 역시 다른 두 가지 방식과 동일한 방식을 사용한다. DBA_Dhaini는 채널 비사용 구간 의 발생을 방지하기 위한 방안으로 모든 $\mathrm{ONU}$ 에 대해 REPORT 메시지를 수신한 후에 즉각적으로 GATE 메시지 를 전송하는 절차를 사용한다. 이러한 방식을 사용할 때 하 나의 스케줄링 사이클은 크게 두 구간으로 분류된다. $\mathrm{ONU}$ 의 REPORT에 대해 즉각적인 GATE 메시지를 전송하여 각 $\mathrm{ONU}$ 가 최대로 최소보장 대역폭만큼의 대역을 할당 받아 전 송하는 구간과 $\mathrm{ONU}$ 의 요구량을 고려하여 추가적인 대역폭 을 할당하는 구간으로 구분할 수 있다. 따라서 DBA_Dhaini 를 사용할 경우 한 스케줄링 사이클 내에서 두 번 전송하는 $\mathrm{ONU}$ 가 존재하게 된다. 스케줄링 사이클 내의 첫 번째 구간 과 두 번째 구간에서 $\mathrm{ONU} i$ 가 할당 받는 대역폭을 각각 $B_{g r a n t, f i r s t}^{i}$ 와 $B_{g r a n t, \text { second }}^{i}$ 로 정의한다.

$$
\begin{gathered}
B_{\text {grant }, \text { first }}^{i}= \begin{cases}B_{\text {request }}^{i}, & \text { for } B_{\text {request }}^{i} \leq B_{M I N} \\
B_{\text {MIN }}, & \text { for } B_{\text {request }}^{i}>B_{M I N}\end{cases} \\
B_{\text {grant }, \text { second }}^{i}= \begin{cases}0 & , \text { for } B_{\text {request }}^{i} \leq B_{M I N} \\
B_{\text {excess }}^{i}, & \text { for } B_{\text {request }}^{i}>B_{M I N}\end{cases}
\end{gathered}
$$

여기서 $B_{\text {excess }}^{i}$ 는 DBA_Assi1, DBA_Assi2와 동일하게 (3)식을 사용하여 얻어진다.

(그림 3(b))는 단일 파장 채널을 사용하는 $\mathrm{EPON}$ 환경에 서 DBA_Dhaini 방식을 사용할 경우 REPORT 메시지와 GATE 메시지가 어떠한 절차를 통해 교환되는지를 나타낸 다. DBA_Dhaini를 적용할 경우 모든 ONU의 REPORT 메 시지에 대해 OLT가 즉각적으로 응답함으로써 채널 비사용 구간을 효율적으로 줄일 수 있다. 그러나 한 스케줄링 사이 클 내에서 두 번 전송하는 $\mathrm{ONU}$ 가 존재하기 때문에 스케줄 링 사이클 내의 전송윈도우 개수가 증가하게 된다. 이러한 전송윈도우 개수의 증가는 전송윈도우 사이에 존재하는 보 호구간의 증가를 초래하고, 채널 사용률을 감소시킨다. 또한 $\mathrm{EPON}$ 은 패킷분할(Packet Fragmentation)을 지원하지 않기 때문에 각 $\mathrm{ONU}$ 에게 할당된 전송윈도우가 모두 패킷 전송 에 사용되지 못한다. 따라서 이러한 사이클 내의 전송윈도 우 개수 증가는 보호 구간과 사용되지 못하고 낭비되는 전 송윈도우의 조각 부분을 증가시켜 효율적인 전송을 어렵게 한다.

\section{3. 제안 방식: DBA-AMTW}

DBA_Dhaini를 사용할 경우 한 스케줄링 사이클 내의 전 송윈도우 증가에 따른 파장 채널 효율성 저하 현상을 감소 시키기 위한 방안으로 본 논문에서는 가변 최대 전송 윈도 우를 이용한 DBA-AMTW 알고리즘을 제안한다. 제안하는 $\mathrm{DBA}-\mathrm{AMTW}$ 는 DBA-Dhaini와 논리적으로 동일한 대역폭 계산 과정을 갖지만 스케줄링 사이클 내에서 모든 $\mathrm{ONU}$ 가 한 번씩만 전송기회를 가지는 특징이 있다. (그림 3(c))는 제안한 $\mathrm{DBA}$ 알고리즘을 나타낸다. 스케줄링 사이클 $j$ 에서 $\mathrm{ONU} i$ 는 개별적인 최대 전송 윈도우의 크기 $T_{M A X}^{i, j}$ 를 가지 고, 이러한 최대 전송 윈도우의 크기는 이전 사이클에서 결 정된다. 최대 전송 윈도우의 크기는 $\mathrm{ONU}$ 마다 다른 값을 가지는 것이 가능하고, 매 사이클 마다 그 값이 새로 갱신 된다. 스케줄링 사이클 $j$ 에 대해 기준 시간인 $t_{r e f}^{j}$ 를 정의하 고 기준 시간 이전에 전송을 시작하는 $\mathrm{ONU}$ 는 개별적인 최 대 전송윈도우를 이용하여 전송을 하고, 기준 시간 이후에 전송을 시작하는 $\mathrm{ONU}$ 는 현재 사이클의 $\mathrm{DBA}$ 계산 결과가 반영된 전송 윈도우를 할당받는다. 따라서 $j$ 번째 스케줄링 사이클에서 기준 시간 $t_{r e f}^{j}$ 는 현재 사이클에서의 DBA 계산 결과 반영 여부를 나타내고 다음과 같이 정의 한다.

$$
t_{\text {ref }}^{j}=t_{\text {cycle end }}^{j-1}+R T T+T_{\text {compute }}
$$

여기서 $t_{\text {cyde end }}^{j-1}$ 와 $T_{\text {compute }}$ 는 각각 $j-1$ 번째 스케줄링 사 이클에서 마지막 $\mathrm{ONU}$ 의 전송윈도우가 종료되는 시점과 $\mathrm{DBA}$ 계산에 필요한 시간을 나타낸다.

각 $\mathrm{ONU}$ 가 할당받게 되는 전송 윈도우의 크기 $T_{\text {trans }}^{i, j}$ 는 
할당 받은 대역폭 $B_{g r a n t}^{i, j}$ 에 의해 결정되고 다음과 같은 관 계를 가진다.

$$
T_{\text {trans }}^{i, j}=B_{\text {grant }}^{i, j} \times 8 / R_{\lambda}
$$

이때 $B_{g r a n t}^{i, j}$ 는 다음의 수식을 통해 결정된다.

- $j$ 번째 스케줄링 사이클에서 $t_{r e f}^{j}$ 이전에 전송하는 $\mathrm{ONU}$

$$
B_{\text {grant }}^{i, j}= \begin{cases}B_{\text {request }}^{i, j}, & \text { for } B_{\text {request }}^{i, j} \leq B_{M I N}^{i, j}, \\ B_{M I N}^{i, j}, & \text { for } B_{\text {request }}^{i, j}>B_{M I N}^{i, j}\end{cases}
$$

- $j$ 번째 스케줄링 사이클에서 $t_{r e f}^{j}$ 이후에 전송하는 $\mathrm{ONU}$

$$
B_{\text {grant }}^{i, j}= \begin{cases}B_{\text {request }}^{i, j}, & \text { for } B_{\text {request }}^{i, j} \leq B_{M I N}^{i, j}, \\ B_{M I I N}^{i, j}+B_{\text {excess }}^{i, j}, & \text { for } B_{\text {request }}^{i, j}>B_{M I N}^{i, j} .\end{cases}
$$

여기서 $B_{M I N}^{i, j}$ 는 $j$ 번째 스케줄링 사이클에서 ONU $i$ 의 최소 보장 대역폭을 의미하고 관련 연구에서 소개된 $\mathrm{DBA}$ 방식들과는 다르게 고정된 값이 아닌 가변적인 값을 가진 다. 또한 $j$ 번째 스케줄링 사이클에서 $\mathrm{ONU} i$ 의 최소 보장 대역폭 $B_{M I N}^{i, j}$ 은 최대 전송 윈도우 $T_{M A X}^{i, j}$ 와 다음과 같은 관 계를 가지고 $j-1$ 번째 사이클에서 그 크기가 결정된다.

$$
T_{M A X}^{i, j}=B_{M I N}^{i, j} \times 8 / R_{\lambda}
$$

- j-1 번째 스케줄링 사이클에서 $t_{r e f}^{j-1}$ 이전에 전송하는 $\mathrm{ONU}$

$$
B_{M N}^{i, j}=B_{M I N}+B_{e x c e s s}^{i, j-1}
$$

- j-1 번째 스케줄링 사이클에서 $t_{r e f}^{j-1}$ 이후에 전송하는 $\mathrm{ONU}$

$$
B_{M I N}^{i, j}=B_{M I N}
$$

여기서 $B_{M I N}$ 은 최소 보장 대역폭에 대한 기준 값으로 (1)식을 통해 얻는다. 또한 $B_{e x c e s s}^{i, j}$ 는 (3)식과 동일한 방법을 통해 얻어진다. 이러한 방법을 사용함으로써 모든 ONU는 기본적으로 $\mathrm{DBA}$ 계산 과정으로 인해 채널 비사용 구간에 서 전송이 가능한 특징을 가지고, 이전 사이클에서의 할당 대역폭과 요구 대역폭이 가변적인 최대 전송 윈도우에 반영 이 되어 모든 $\mathrm{ONU}$ 의 요구량을 고려한 $\mathrm{DBA}$ 가 가능하다.

\section{4. 성능 평가}

제안하는 $\mathrm{DBA}$ 방식의 성능을 분석하고 기존에 연구된 $\mathrm{DBA}$ 방식들간의 성능을 비교하기 위해 다음과 같은 시뮬
레이션 환경을 가정하였다. ONU의 개수는 32 개로 하였고, 16 개의 $\mathrm{ONU}$ 는 고정된 $10 \mathrm{Mbps}$ 의 트래픽을 생성하고 나머 지 16 개의 $\mathrm{ONU}$ 는 $5 \mathrm{Mbps}$ 에서 $100 \mathrm{Mbps}$ 까지 $5 \mathrm{Mbps}$ 단위로 변화하면서 트래픽을 생성한다. 상향 및 하향 전송을 위해 각각 1 개씩의 파장채널을 사용하고, 하나의 파장 채널의 전 송률은 $1 \mathrm{Gbps}$ 로 가정하였다. 전송 지연시간은 $100 \mu \mathrm{s}, \mathrm{DBA}$ 계산 수행 시간은 $200 \mu \mathrm{s}$ 로 설정하였다. 또한 상향전송을 위 한 보호시간과 최대 사이클 시간은 각각 $1 \mu \mathrm{s}$ 와 $2 \mathrm{~ms}$ 를 사용 하였다. 각 $\mathrm{ONU}$ 는 $10 \mathrm{Mbytes}$ 의 버퍼 크기를 가진다고 가정 하였고, 각 $\mathrm{ONU}$ 에서 생성되는 $\mathrm{EF}$ 트래픽은 프아송 (Poisson) 분포를 가지고 패킷의 크기는 70bytes로 생성하였 다. 또한 $\mathrm{AF}$ 및 $\mathrm{BE}$ 트래픽은 실제 환경을 고려하여 자기상 관(self-similar) 특성을 가지게 생성하였고 패킷의 크기는 64bytes와 1518bytes 사이에서 균일한 분포를 가지도록 하 였다. 전송의 우선순위를 결정하기 위한 intra-ONU 스케줄 링 방식으로 $\mathrm{PQ}$ 방식을 고려하였고, inter-ONU 스케줄링 방식으로 Round Robin 방식을 사용하였다. DBA_Assi2의 경우만 예외적으로 $\mathrm{ONU}$ 의 전송 순서가 바뀌기 때문에 DBA_Assi2의 경우 대역폭 할당 알고리즘에 의한 전송 순 서를 따른다.

각 $\mathrm{DBA}$ 방식에 대한 지연 시간 성능을 (그림 4)에서 나 타내었다. 제안하는 DBA-AMTW가 비교 방식에 비해 중간 정도의 트래픽 부하에서 높은 성능을 나타내는 것을 확인할 수가 있다. 0.3까지의 트래픽 부하에서 DBA_Assi2, DBA_Dhaini 그리고 DBA-AMTW가 동일한 성능을 나타내 는 것을 확인할 수 있는데 이는 세 가지 방식이 낮은 트래 픽 부하에서는 IPS에 기반을 둔 $\mathrm{DBA}$ 방식들과 동일하게 동작하기 때문이다. 또한 높은 트래픽 부하에서도 세 가지 방식의 성능이 유사한 것을 확인할 수가 있는데, 각 방식에 서 각 $\mathrm{ONU}$ 가 할당 받는 대역폭의 크기와 전송순서는 차이 를 보이지만 논리적으로 각 $\mathrm{ONU}$ 가 할당 받는 대역폭은 세 가지 방식에서 동일하기 때문이다.

멀티 서비스를 고려하여 각 서비스에 해당하는 패킷의 지 연시간에 대한 결과를 시뮬레이션을 통해 비교하였다. (그림

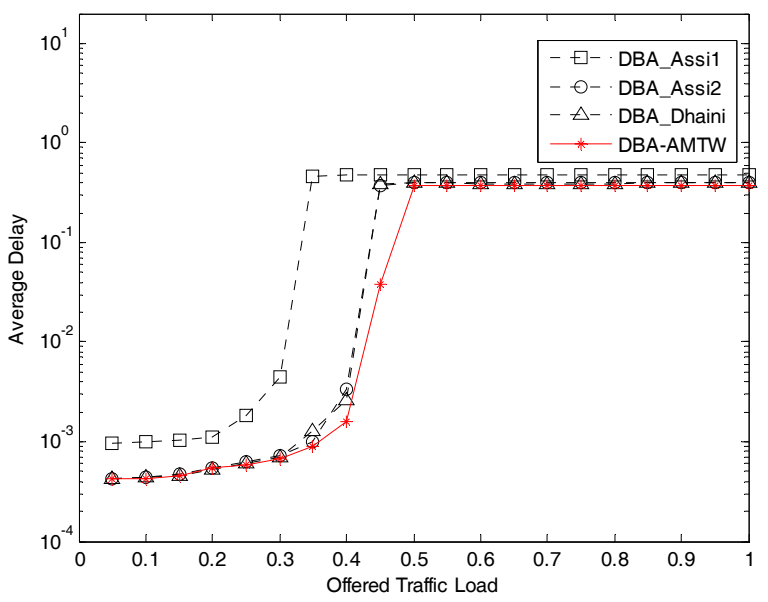

(그림 4) 평균 지연시간 


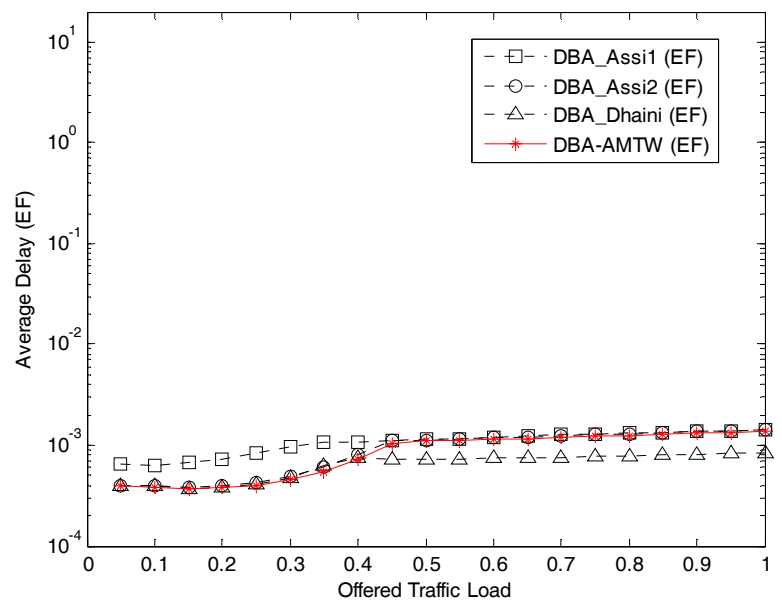

(그림 5) $\mathrm{EF}$ 트래픽에 대한 평균 지연시간

5)는 $\mathrm{EF}$ 트래픽에 대한 지연시간 결과를 나타낸다. $\mathrm{EF}$ 트 래픽의 경우 낮은 트래픽 부하에서 DBA_Assi2, DBA_Dhaini, $\mathrm{DBA}-\mathrm{AMTW}$ 가 모두 동일한 결과를 나타내지만, 높은 부하 에서는 DBA_Dhaini가 가장 좋은 성능을 나타내는 것을 확 인할 수 있다. EPON 환경에서 DBA_Dhaini를 적용할 경우 하나의 스케줄링 사이클 내에서 두 번 전송 기회를 가지는 $\mathrm{ONU}$ 가 존재하게 되고, 이러한 $\mathrm{ONU}$ 의 경우 내부 스케줄링 방식에 의해 $\mathrm{EF}$ 트래픽을 우선적으로 전송하기 때문에 다 른 $\mathrm{ONU}$ 에 비해 $\mathrm{EF}$ 트래픽의 지연시간 성능이 개선된다. (그림 6(a))는 절반의 ONU는 $10 \mathrm{Mbps}$ 의 트래픽을 생성하고 나머지의 $\mathrm{ONU}$ 는 $75 \mathrm{Mbps}$ 의 트래픽을 생성하는 환경에서 $10 \mathrm{Mbps}$ 의 트래픽을 생성하는 $\mathrm{ONU}$ 의 $\mathrm{EF}$ 트래픽 지연시간 에 대한 누적분포를 나타낸다. $\mathrm{EF}$ 트래픽의 경우 가장 높은 우선순위를 가지고 처리되기 때문에 할당받는 대역폭에 관 계없이 제안한 방식과 비교 방식이 모두 거의 동일한 결과 를 보이는 것을 확인할 수 있다. (그림 6(a))와 동일한 환경 에서 $75 \mathrm{Mbps}$ 의 트래픽을 생성하는 $\mathrm{ONU}$ 의 $\mathrm{EF}$ 트래픽 지연 시간에 대한 누적빈도를 (그림 6(b))에서 볼 수 있다. 해당

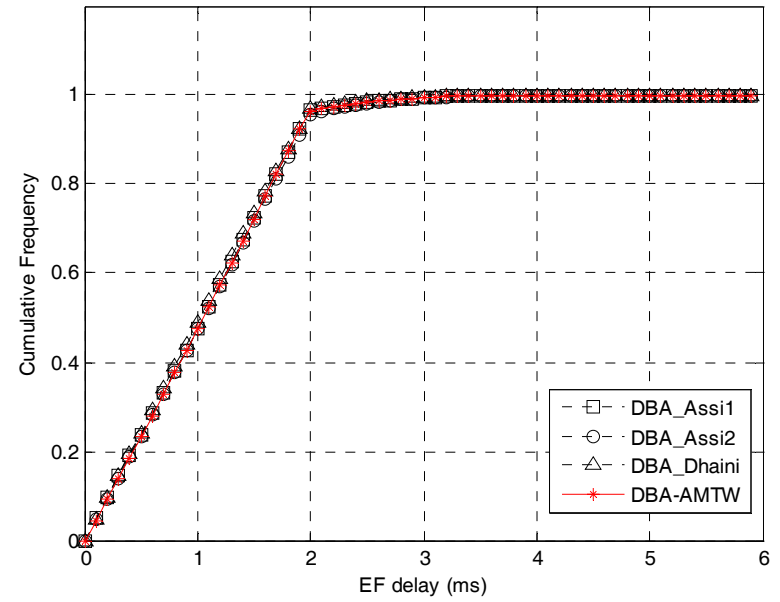

(a) $10 \mathrm{Mbps}$ 를 생성하는 $\mathrm{ONU}$ 의 $\mathrm{EF}$ 트래픽 지연시간에 대한 누적빈도
환경에서 DBA_Dhaini를 적용할 경우 $75 \mathrm{Mbps}$ 를 생성하는 $\mathrm{ONU}$ 는 한 스케줄링 사이클 동안 두 번 전송하는 기회를 얻게 된다. 이러한 특성으로 인해 최소보장 대역폭보다 많 은 대역폭을 요구하는 $\mathrm{ONU}$ 의 $\mathrm{EF}$ 트래픽에 대한 지연시간 결과가 다른 방식에 비해 개선된다. 그러나 (그림 6(a))처럼 시스템 전체에서 보장할 수 있는 $\mathrm{EF}$ 트래픽의 지연결과는 네 가지 방식 모두 동일하다.

(그림 7과 8)은 각각 $\mathrm{AF}$ 와 $\mathrm{BE}$ 트래픽에 대한 지연시간 결과를 나타낸다. 낮은 트래픽을 생성하는 환경에서 DBA_Assi1의 경우 채널 비사용 구간을 효율적으로 활용할 수 없는 특징으로 인해 가장 낮은 성능을 보이는 것을 확인 할 수 있다. $\mathrm{AF}$ 트래픽과 $\mathrm{BE}$ 트래픽의 경우 $\mathrm{ONU}$ 내부 스 케줄러에 의해 버퍼에 있는 $\mathrm{EF}$ 트래픽이 모두 전송된 후에 전송되는 특징을 가진다. 따라서 파장 채널을 가장 효율적 으로 활용하는 DBA-AMTW의 경우 다른 두 가지 방식에 비해 트래픽 부하 별로 성능이 개선됨을 확인할 수 있다. 특히 이러한 채널 사용률의 개선에 대한 결과는 $\mathrm{BE}$ 트래픽 의 지연시간을 통해 쉽게 확인할 수가 있다.

트래픽 변화에 따른 처리율에 대한 결과는 (그림 9)에서 관찰할 수 있다. DBA_Assi1의 경우 채널 비사용 구간 발생 으로 인해 가장 낮은 성능을 보인다. 제안 방식의 경우 비교 방식인 DBA_Assi1, DBA_Assi2, DBA_Dhaini에 비해 절반 의 $\mathrm{ONU}$ 가 $100 \mathrm{Mbps}$ 의 트래픽을 생성하는 환경에서 각각 $27.9 \%, 6.1 \%, 4.1 \%$ 의 성능 향상을 보이고 있다. 그림에서 DBA_Assi1의 경우 35Mbps의 트래픽 부하에서 DBA_Assi2, DBA_Dhaini의 경우 각각 $40 \mathrm{Mbps}$ 에서 처리율이 포화(saturation) 되는 현상을 관찰할 수 있다. 이러한 현상은 포화점보다 높 은 트래픽 부하가 발생할 경우 $\mathrm{ONU}$ 가 전송할 패킷을 즉각 적으로 처리하지 못 하는 것을 나타내고, 지연시간이 해당 포화점에서 급격히 증가하는 현상과 동일하다. 포화점 보다 높은 트래픽 부하에서 $\mathrm{ONU}$ 의 내부 큐에 입력되는 패킷들 은 한정된 큐의 크기로 인하여 저장되지 못하고 버려지는 현상이 발생하게 된다. (그림 10)은 이러한 패킷 손실에 대

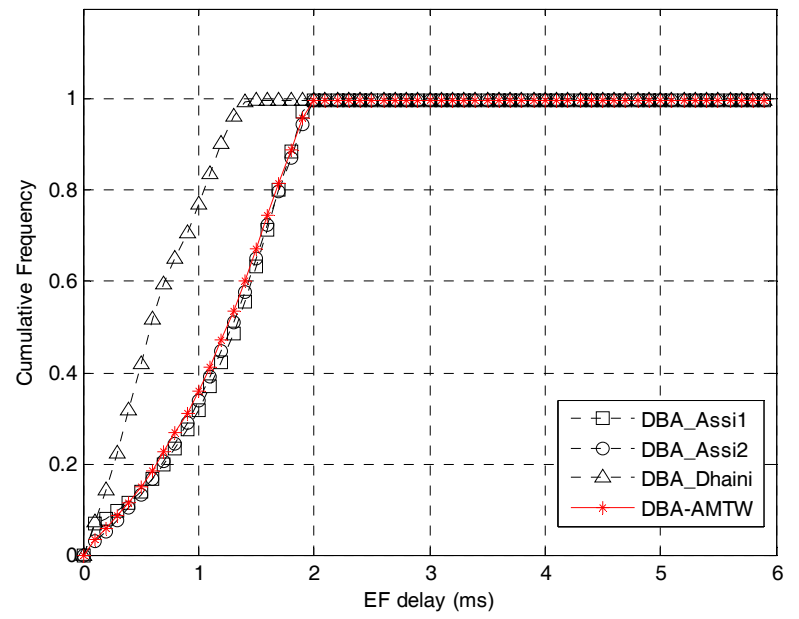

(b) $75 \mathrm{Mbps}$ 를 생성하는 $\mathrm{ONU}$ 의 $\mathrm{EF}$ 트래픽 지연시간에 대한 누적빈도

(그림 6) EF 트래픽 지연시간에 대한 누적빈도 


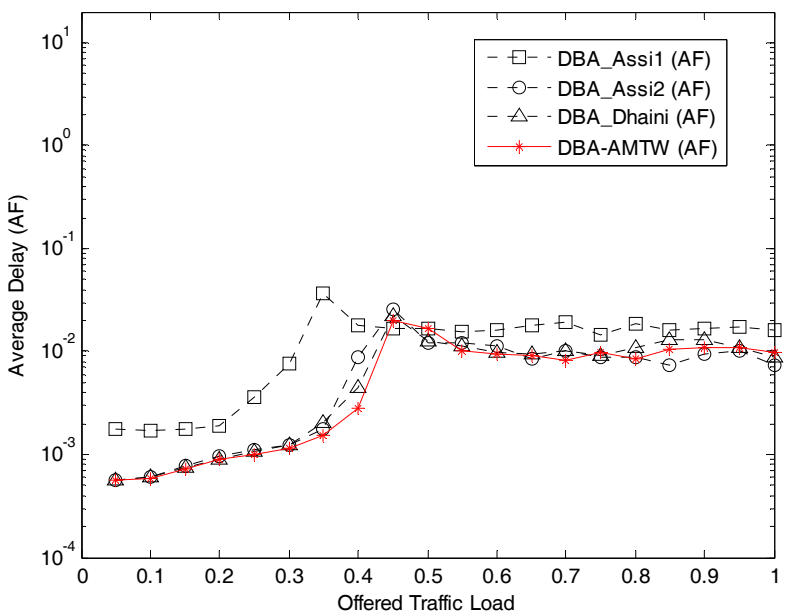

(그림 7) AF 트래픽에 대한 평균 지연시간

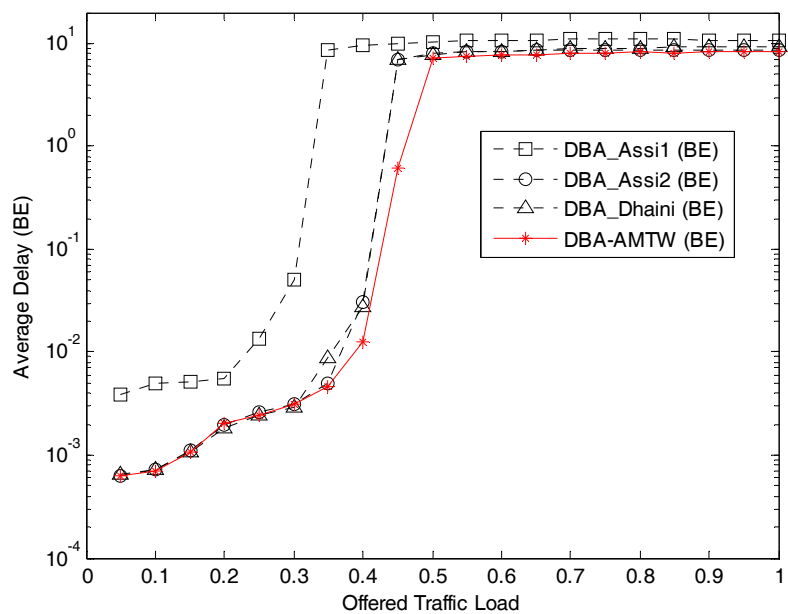

(그림 8) BE 트래픽에 대한 평균 지연시간

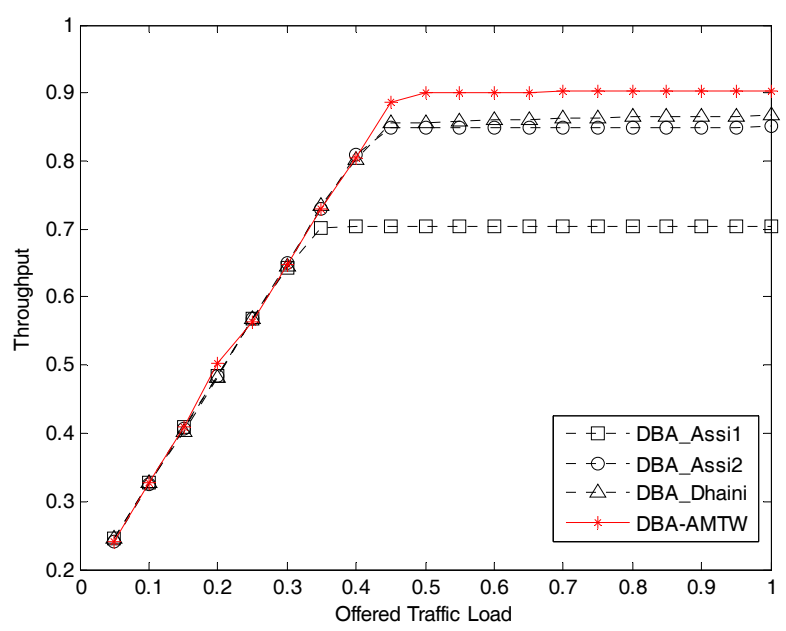

(그림 9) 트래픽 변화에 대한 처리율

한 결과를 나타낸다. ONU가 생성하는 트래픽 부하의 크기 변화에 따라 한 스케줄링 사이클 내에서 손실된 패킷들의 평균적인 양을 나타내고 있다. 제안한 DBA-AMTW가 채널

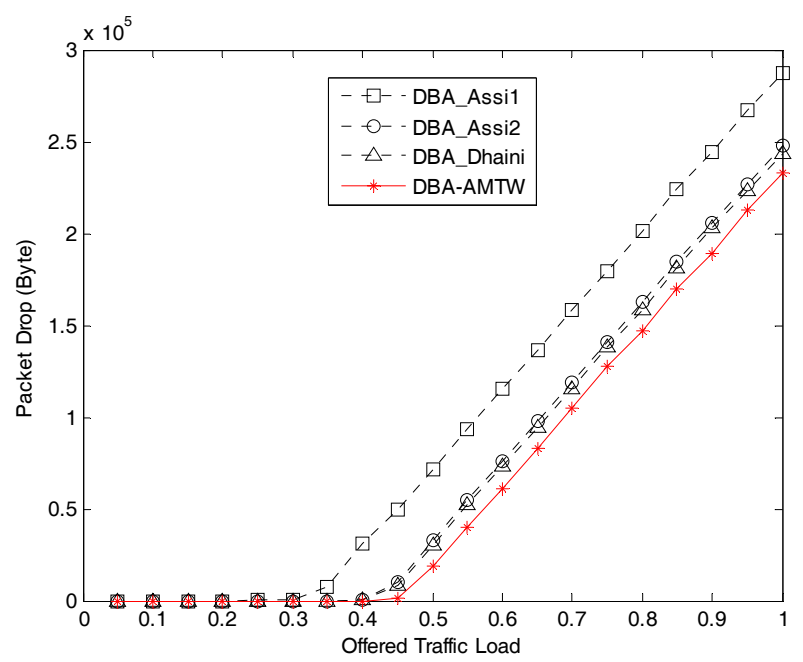

(그림 10) 하나의 스케줄링 사이클 내에서 발생하는 평균적인 패킷 손실

을 가장 효율적으로 사용하기 때문에 평균적인 패킷 손실에 서도 가장 우수한 성능을 나타내는 것을 확인할 수 있다.

\section{5. 결 론}

본 논문에서는 IPS 기법에 기반을 둔 $\mathrm{DBA}$ 알고리즘의 단점인 채널 비사용 구간을 줄이기 위한 방안으로 가변 최 대 전송 윈도우를 이용한 동적 대역폭 할당 알고리즘을 제 안하였다. 각 $\mathrm{ONU}$ 에게 독립적인 가변 최대 전송 윈도우를 적용함으로써 즉각적인 GATE 메시지 할당이 가능하여 채 널을 효율적으로 사용할 수 있고, 동시에 모든 ONU의 $\mathrm{REPORT}$ 메시지를 고려한 $\mathrm{DBA}$ 가 가능하여 합리적인 전송 윈도우 할당이 가능하다. 시뮬레이션을 통해 제안한 가변 최대 전송 윈도우를 이용한 $\mathrm{DBA}$ 방식이 기존 방식들에 비 해 지연시간에 대한 성능 및 처리율을 개선시키는 것을 확 인하였고, 한정된 큐의 크기로 인해 발생하는 패킷 손실도 줄임을 확인하였다. 가변 최대 전송 윈도우와 기준시간을 적용하였으며 논리적으로는 기존의 IPS에 기반을 둔 $\mathrm{DBA}$ 방식들과 동일한 $\mathrm{DBA}$ 계산 과정을 거치기 때문에 다양한 $\mathrm{DBA}$ 알고리즘의 적용이 가능하다. 본 논문에서는 각 $\mathrm{ONU}$ 의 최소 전송률을 보장하기 위한 $\mathrm{DBA}$ 방식만을 적용하고 있으나 향후 네트워크의 요구사항들을 모두 만족시키기 위 해 최적화된 $\mathrm{DBA}$ 방식에 대한 연구가 필요하다. 또한 다중 파장 채널을 사용하는 $\mathrm{EPON}$ 환경 및 유무선 통합 환경을 위한 $\mathrm{DBA}$ 에 대한 연구가 추가적으로 요구된다.

\section{참 고 문 헌}

[1] M. Abrams, P.C. Becker, Y. Fujimoto, V. O'Byrne and D. Piehler, "FTTP Deployments in the United States and Japan-Equipment Choices and Service Provider Imperatives," J. Lightw. Technol., vol.23, no.1, pp. 236-246, Jan. 2005. 
[2] L. Hutcheson, "FTTx: Current Status and the Future," IEEE Commun. Mag., vol.46, no.7, pp.90-95, Jul. 2008.

[3] G. Shen, R.S. Tucker and C.-J. Chae, "Fixed Mobile Convergence Architectures for Broadband Access: Integration of EPON and WiMAX," IEEE Commun. Mag., vol.45, no.8, pp.44-50, Aug. 2007.

[4] G. Kramer and G. Pesavento, "Ethernet Passive Optical Network (EPON): Building a Next-Generation Optical Access Network," IEEE Commun. Mag., vol.40, no.2, pp.66-73, Feb. 2002.

[5] C. Assi, M. Maier and A. Shami, "Toward Quality of Service Protection in Ethernet Passive Optical Networks: Challenges and Solutions," IEEE Network, vol.21, no.5, pp.12-19, Sept.-Oct. 2007.

[6] J. Zheng and H.T. Mouftah, "Media Access Control for Ethernet Passive Optical Networks: An Overview," IEEE Commun. Mag., vol.43, no.2, pp.145-150, Feb. 2005.

[7] M.P. McGarry, M. Maier and M. Reisslein, "Ethernet PONs: A Survey of Dynamic Bandwidth Allocation (DBA) Algorithms," IEEE Commun. Mag., vol.42, no.8, pp.S8-S15, Aug. 2004.

[8] G. Kramer, B. Mukherjee, and G. Pesavento, "IPACT: A Dynamic Protocol for an Ethernet PON(EPON)," IEEE Commun. Mag., vol.40, no.2, pp.74-80, Feb. 2002.

[9] Y. Zhu and M. Ma, "IPACT with Grant Estimation(IPACT-GE) Scheme for Ethernet Passive Optical Networks," J. Lightw. Technol., vol.26, no.14, pp.2055-2063, Jul. 2008.

[10] C.M. Assi, Y. Ye, S. Dixit and M. A. Ali, "Dynamic Bandwidth Allocation for Quality-of-Service Over Ethernet PONs," IEEE J. Sel. Areas Commun., vol.21, no.9, pp.1467-1477, Nov. 2003.

[11] A. R. Dhaini, C. M. Assi, M. Maier and A. Shami, "Dynamic Wavelength and Bandwidth Allocation in Hybrid TDM/WDM EPON Networks," J. Lightw. Technol., vol.25, no.1, pp.277-286, Jan. 2007.

[12] Y. Lou and N. Ansari, "Bandwidth Allocation for Multiservice Access on EPONs," IEEE Commun. Mag., vol.43, no.2 pp.S16-S21, Feb. 2005.

[13] IETF RFC 2475, "An Architecture for Differentiated Services," Dec. 1998.

[14] M. P. McGarry, M. Reisslein, C.J. Colbourn, M. Maier, F. Aurzada, and M. Scheutzow, "Just-in-Time Scheduling for Multichannel EPONs," J. Lightw. Technol., vol.26, no.10, pp.1204-1216, May 2008.

[15] J. Zheng and H.T. Mouftah, "Adaptive Scheduling Algorithms for Ethernet Passive Optical Networks," IEE Proc.-Commun., vol.152, no.5, Oct. 2005.
[16] 이상호, 이태진, 정민영, 이유호, 추현승, "EPON에서 효율 적 대역폭할당을 위한 최대 전송 윈도우 크기의 동적변화 기법,” 한국인터넷정보학회 논문지, vol. 8, no. 4, pp. 41-49, Aug. 2007.

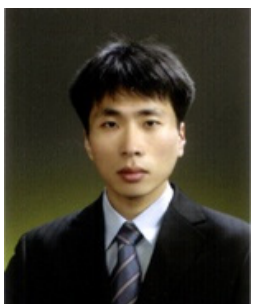

조 승 무

e-mail:smcho@ece.skku.ac.kr

2006년 한양대학교 전자전기컴퓨터공학부 (학사)

2009년 성균관대학교 정보통신공학부(공학 석사)

2009년 현 재 삼성전자 $\mathrm{DMC}$ 부문 무선 사업부 연구원

관심분야: 광 네트워크, 부분 주파수 재사용, 이동통신 네트워크 등

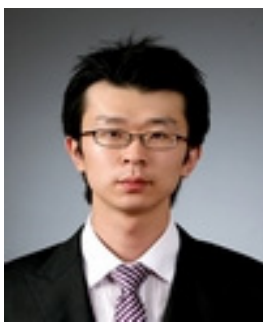

오 창 영

e-mail :ohchy@ece.skku.ac.kr

2008년 한양대학교 전자전기컴퓨터공학부 (학사)

2008년 3월 현 재 성균관대학교 정보 통신공학부 공학석사과정

관심분야: 협력통신, 무선 LAN, Femtocell, 광 네트워크 등

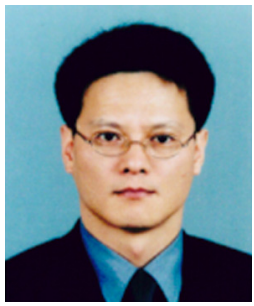

\section{정 민 영}

e-mail : mychung@ece.skku.ac.kr 1990년 KAIST 전기 및 전자공학과(학사) 1994년 KAIST 전기 및 전자공학과(공학 석사)

1999년 KAIST 전기 및 전자공학과(공학 박사)

1999년 2002년 ETRI 선임연구원

2002년 현 재 성균관대학교 정보통신공학부 부교수

관심분야: 이동통신 네트워크, 무선 LAN/PAN, 광 네트워크, IP 라우터 시스템, 유/무선 홈 네트워크 등 


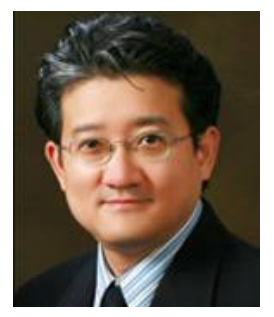

추 현 승

e-mail : choo@skku.edu

1988년 성균관대학교 수학과(학사)

1990년 Univ. of Texas 컴퓨터공학과(공 학석사)

1996년 Univ. of Texas 컴퓨터공학과(공 학박사)

1998년 현 재 성균관대학교 정보통신공학부 부교수

2005년 현 재 지식경제부 ITRC 지능형 HCI융합연구센터장

관심분야: 유/무선/광네트워킹, 모바일컴퓨팅, 센서네트워크, 임 베디드SW, 그리드컴퓨팅 등

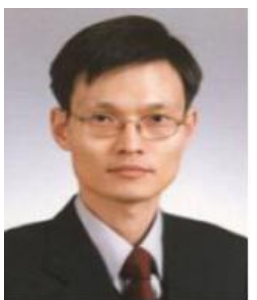

\section{이 태 진}

e-mail : tjlee@ece.skku.ac.kr

1989년 연세대학교 전자공학과(학사)

1991년 연세대학교 전자공학과(공학석사)

1995년 Univ. of Michigan, Ann Arbor, $\mathrm{EECS}$ (공학석사)

1999년 Univ. of Texas at Austin, ECE (공학박사)

1999년 2001년 삼성전자 중앙 연구소 책임 연구원

2001년 현 재 성균관대학교 정보통신공학부 부교수

관심분야: 통신 네트워크/시스템의 성능분석 및 설계, 무선

PAN/LAN/MAN, Ad-hoc/RFID/센서 네트워크, 광 네트 워크 등 